\section{References}

Anderson, T. W. (1958). Multivariate Analysis. London, Wiley.

Billewicz, W. Z. et al. (1969). Quarterly fournal of Medicine, 38, 255.

Clark, F., and Horn, D. B. (1965). Fournal of Clinical Endocrinology, 25, 39. Medicine, 28, 211.
Fitzgerald, L. T., Overall, J. E., and Williams, C. M. (1966). American Fournal of Roentgenology, 97, 901.

Fraser, R., Hobson, Q. J. C., Arnott, D. G., and Emery, E. W. (1953). Quarterly Fournal of Medicine, 22, 99.

Oddie, T. H. (1971). Fournal of Clinical Endocrinology, 32, 167.

Overall, J. E., and Williams, C. M. (1963). Fournal of the American Medical Association, 183, 307.

\title{
Value of an ACTH Test in Assessing Hypothalamic- Pituitary-Adrenocortical Function in Glucocorticoid-treated Patients
}

\author{
HENRIK KEHLET, CHRISTIAN BINDER
}

British Medical fournal, 1973, 2, 147-149

\section{Summary}

Forty-eight patients receiving glucocorticoid treatment were tested with ACTH stimulation using $\alpha^{1},{ }^{24}$ ACTH (tetracosactrin). All patients subsequently underwent non-acute major surgery without any glucocorticoid administration, and their clinical course and plasma corticosteroids were followed closely. No case of adrenocortical insufficiency was observed. A highly significant correlation was found between the preoperative adrenocortical response to ACTH and the hypothalmic-pituitary-adrenocortical (H.P.A.) response to surgery. A normal response to ACTH stimulation was never followed by a greatly impaired H.P.A. response to surgery. It seems that a simple ACTH stimulation test is reliable in predicting the integrated H.P.A. response to major stress in glucocorticoid-treated patients.

\section{Introduction}

It has been shown that treatment with glucocorticoids may cause impaired function of the hypothalamic-pituitary adrenocortical (H.P.A.) axis (Treadwell et al., 1963). Generally, the insulin and the pyrogen tests are used to evaluate the integrated function of the H.P.A. axis. These tests show whether a patient is able to respond to stress situations and they are used to determine if a glucocorticoid-treated patient needs extra glucocorticoids in such situations (Plumpton et al., 1969). However, these tests are time consuming and have unpleasant side effects, which make them less suitable for routine use.

In the present study we show that a simple preoperative ACTH stimulation test can predict the response of the H.P.A. axis to the stress of major surgery.

\section{Material and Method}

Three groups of patients and normal subjects were studied. Twenty-eight were patients who had never received glucocorticoids who were studied during major surgical procedures (see table), 26 were normal subjects who were stimulated

Medical Department $F$ and Surgical Department D, Gentofte Hospital, University of Copenhagen, DK-2900 Hellerup, Denmark HENRIK KEHLET, M.D. CHRISTIAN BINDER, M.D.
Operations Performed on 28 Normal Patients (Never Received Glucocorticoids) and on 48 Glucocorticoid-treated Patients

\begin{tabular}{|c|c|c|}
\hline & Normals & Glucocortoid-treated \\
\hline $\begin{array}{lcc}\text { Cholecystectomy } & \ldots & \ldots \\
\text { Splenectomy.. } & \ldots & \ldots \\
\text { Gastrectomy } & \ldots & \ldots \\
\text { Colectomy } \\
\text { Pulmonectomy } & \ldots & \ldots \\
\text { Gynaecological laparotomy . } \\
\text { Kidney or ureter } & \text { operation. }\end{array}$ & $\begin{array}{r}7 \\
1 \\
13 \\
7 \\
= \\
-\end{array}$ & $\begin{array}{r}7 \\
17 \\
2 \\
11 \\
5 \\
2 \\
4\end{array}$ \\
\hline
\end{tabular}

with ACTH (see below), and 48 were patients currently receiving treatment with glucocorticoids who were investigated with both an ACTH test and during a major surgical procedure, (see table). The duration of glucocorticoid treatment and the daily dose of prednisone or equivalents are shown in fig. 1. The ACTH stimulation test was carried out as follows: from four days to one day before surgery $250 \mu \mathrm{g}$ of $\alpha^{1,24}$ ACTH $^{*}$ (tetracosactrin) was injected intravenously at 8 a.m. in the fasting patient. Blood samples for plasma corticosteroid determinations were drawn immediately before and 30 minutes after the injection. Treatment with glucocorticoids was stopped 36 hours before the beginning of the operation. From the time oral glucocorticoids were stopped and for 72 hours postoperatively the patients were observed carefully for signs of adrenocortical insufficiency, everything being pre*According to the nomenclature for various analogs of ACTH (Li, 1959).

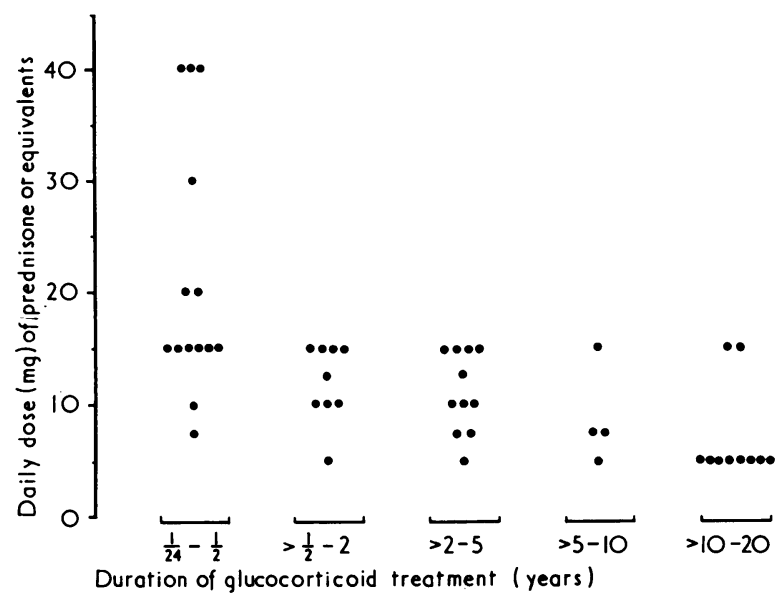

FIG. 1-Duration of treatment in years and daily dose of prednisone or Fig. 1-Duration of treatment in years and daily dose of prednisone or equivalents in $\mathrm{mg}$ in
during major surgery. 
pared for immediate therapy directed against adrenocortical insufficiency. After this period treatment with glucocorticoids was started again. All patients gave informed consent to the examinations.

The patients were anaesthetized with thiopental, suxamethonium, halothane, and $\mathrm{N}_{2} \mathrm{O}+\mathrm{O}_{2}$ or neurolept anaesthesia. The interval between the induction of anaesthesia and the start of the operation was always less than 20 minutes. Blood samples for plasma corticosteroid determinations were taken at the time of skin incision, one hour later, and at intervals throughout 24 hours postoperatively. The duration of operation was always more than one hour. Plasma corticosteroids were measured fluorometrically by a modification of Mattingly's (1962) method (Binder, 1972).

\section{Results}

\section{PATIENTS NOT TREATED WITH GLUCOCORTICOIDS}

In 26 normal subjects studied with an ACTH stimulation test plasma corticosteroids increased by an average of 20 (range 12 to 31 ) to an average concentration of $37 \mu \mathrm{g} / 100 \mathrm{ml}$ (range 24 to $60 \mu \mathrm{g} / 100 \mathrm{ml}$ ) 30 minutes after ACTH injection. In 28 patients studied during major surgery the mean concentration of plasma corticosteroids one hour after skin incision was 41 $\mu \mathrm{g} / 100 \mathrm{ml}$ (range 30 to $60 \mu \mathrm{g} / 100 \mathrm{ml}$ ). Three to four hours after skin incision the mean concentration of corticosteroids in plasma was $46 \mu \mathrm{g} / 100 \mathrm{ml}$ (range 26 to $74 \mu \mathrm{g} / 100 \mathrm{ml}$ ). Accordingly the following responses were regarded as normal.

ACTH Test.-Increase in plasma corticosteroids by more than 12 and to a concentration of more than $24 \mu \mathrm{g} / 100 \mathrm{ml} 30$ minutes after ACTH injection.

H P.A. Response to Major Surgery.-Plasma corticosteroids should be higher than $30 \mu \mathrm{g} / 100 \mathrm{ml}$ one hour, and higher than $26 \mu \mathrm{g} / 100 \mathrm{ml} \mathrm{3-4}$ hours after skin incision.

\section{GLUCOCORTICOID-TREATED PATIENTS}

Of 48 glucocorticoid-treated patients, 17 showed a normal and 31 an impaired response to ACTH. Of the 17 patients with a normal response to ACTH, 13 also showed a normal H.P.A. response to surgery measured one hour after skin incision. Plasma corticosteroid concentrations in the remaining four patients were $23,27,28$, and $28 \mu \mathrm{g} / 100 \mathrm{ml}$ one hour after skin incision and thus only slightly lower than normal. Three hours after skin incision plasma corticosteroid concentrations in these four patients were $28,23,31$, and $34 \mu \mathrm{g} / 100$ $\mathrm{ml}$, and thus within normal range in three and slightly subnormal in one patient. All patients with a normal response to ACTH and operation one hour after skin incision also showed a normal response 3-4 hours after skin incision. Of the 31 patients with an impaired response to ACTH, 25 also showed an impaired H.P.A. response to operation one hour after skin incision. Sixteen of the 25 patients had normal plasma corticosteroid concentrations $3-4$ hours after skin incision. The patients with an impaired response to ACTH but normal response one hour after skin incision also showed a normal response 3-4 hours after skin incision.

The correlation between increase in plasma corticosteroids after ACTH and the concentration of corticosteroids in plasma one hour after skin incision is shown in fig. 2. The correlation between the concentration of corticosteroids in plasma 30 minutes after injection of ACTH and the concentration of corticosteroids in plasma one hour after skin incision is shown in fig. 3. It appears that there is a highly significant $(P<0.001)$ and a high degree ( $r=0.83$ and 0.82 ) of correlation between the preoperative adrenocortical response to ACTH and the integrated H.P.A. response to major surgical stress. In no case

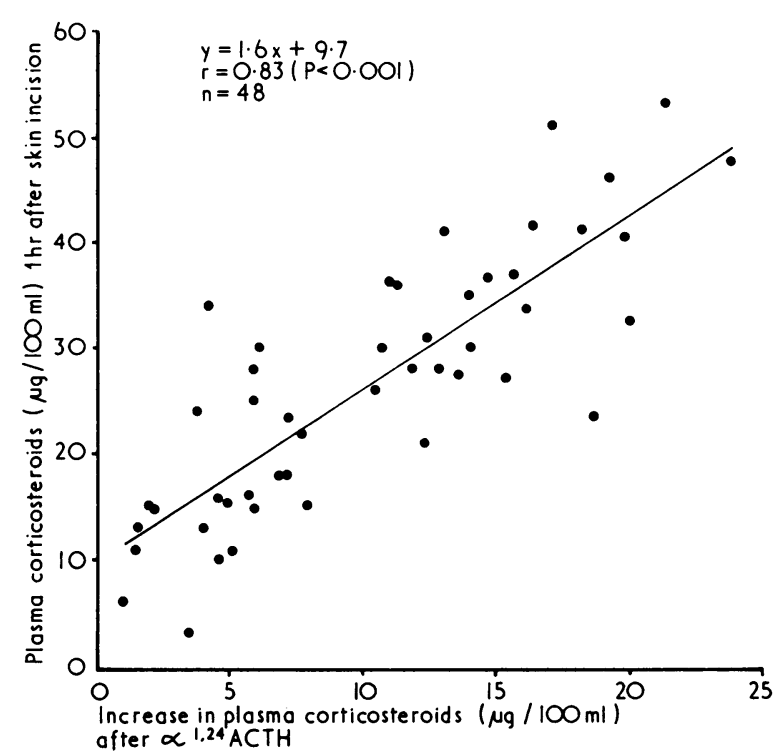

FIG. 2-Comparison between the adrenocortical response to $250 \mathrm{\mu g}$ of $\alpha^{1.24} \mathrm{ACTH}$ and the hypothalamic-pituitary-adrenocortical response to major surgery, measured one hour after skin incision.

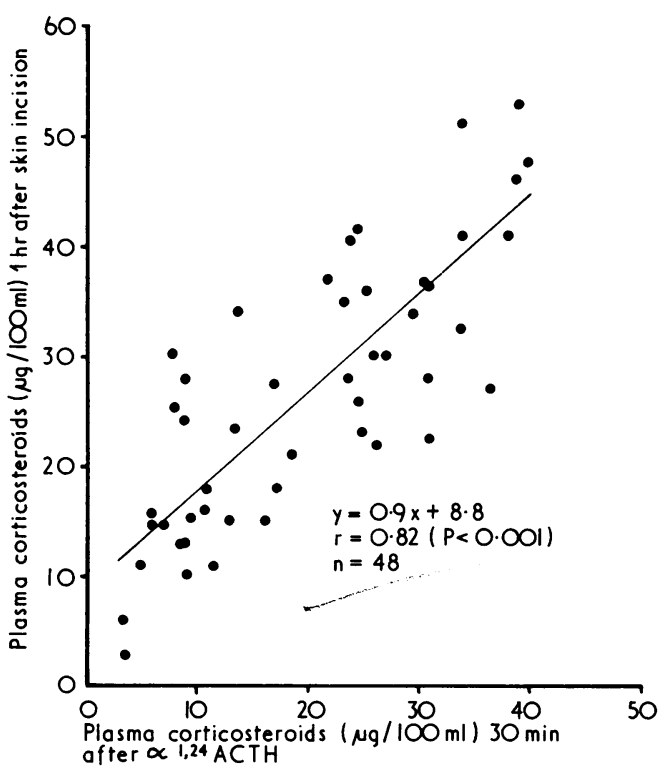

FIG. 3-Comparison between the adrenocortical response to $250 \mathrm{\mu g}$ of $\alpha^{1.24}$ ACTH 30 min after injection and the hypothalamic-pituitary-adrenocortical response to major surgery, measured one hour after skin incision.

was a normal response to ACTH followed by a greatly reduced H.P.A. response to operation.

The results of the ACTH stimulation test were also compared to the concentrations of plasma corticosteroids 3-4 hours after skin incision, showing a similar high degree of correlation $(r=0.74, P<0.001$; and $r=0.75, P<0.001$, respectively). Again, none of the patients with a normal response to ACTH elicited any greatly impaired H.P.A. response to operation.

None of the patients showed any symptoms of manifest acute adrenocortical insufficiency and none were given substitution with glucocorticoids. The clinical course in these patients has been described elsewhere (Kehlet and Binder, 1973). 
Discussion

The purpose of evaluating the hypothalamic-pituitaryadrenocortical (H.P.A.) function in glucocorticoid-treated patients is to select those patients with impaired function who will have to have supplementary glucocorticoids in stress situations.

Some authors have warned against the use of an ACTH stimulation test in the assessment of the H.P.A. function as it describes only the adrenocortical function and not the hypothalamic-pituitary function, which has been reported to be suppressed independently (Engel et al., 1958; Holub et al., 1959; Robinson et al., 1962; Brinck-Johnsen et al., 1963; Jasani et al., 1967). In some of these studies, however, the intense and prolonged ACTH stimulation may have promoted an adrenocortical response, which should not be compared to the response to the shorter and more physiological H.P.A. test.

The present investigation was carried out in order to show whether the response to a short stimulation with ACTH correlates with the integrated H.P.A. function during subsequent major surgery in glucocorticoid-treated patients. Our results show a high degree of correlation, and in no case was a normal preoperative response to ACTH followed by a greatly impaired H.P.A. response to surgery. In a similar study, Jasani et al. (1968) found a slightly impaired H.P.A. response to surgery in a few glucocorticoid-treated patients who showed a normal response to ACTH but a subnormal response to the insulin test. Obviously, the insulin test is the most sensitive test in the assessment of the H.P.A. function (Jasani et. al., 1967; Plumpton et al., 1969; British
Medical fournal, 1970). But based on the results of the present study it seems to us most unlikely that a preoperative normal response to ACTH will be followed by a greatly impaired H.P.A. response to major stress and it is concluded that a simple ACTH test is of value in predicting the integrated H.P.A. response to major stress in glucocorticoid-treated patients.

It is also to be expected that the ACTH test will be of value in patients previously treated with glucocorticoids, as the hypothalamic-pituitary system is restored before the adrenal cortex after cessation of glucocorticoid therapy (Graber et al., 1965).

\section{References}

Binder, C. (1972). Acta Endocrinologica (Kobenhavn), 69, 355

Brinck-Johnsen, T., Solem, J. H., Brinck-Johnsen, K., and Ingvaldsen, P. (1963). Acta Medica Scandinavica, 173, 129.

British Medical fournal, 1970, 1, 644.

Engel, E., Demenat, J. C., Brichant, J., and Riondel, A. M. (1958). Helvetica Medica Acta, 25, 552 .

Graber, A. L., Ney, R. L., Nicholson, W. E., Island, D. P., and Liddle, G. W. (1965). Fournal of Clinical Endocrinology and Metabolism, 25, 11.

Holub, D. A., Jailer, J. W., Kitay, J. I., and Frantz, A. G. (1959). fournal of Clinical Endocrinology and Metabolism, 19, 1540.

Jasani, M. K., et al. (1967). Quarterly fournal of Medicine, 36, 261.
Jasani, M. K., et al. (1968). Ouarterly fournal of Medicine, 37, 407.

Kehlet, H., and Binder, C. (1973). British fournal of Anaesthesia. Submitted for publication.

Li, C. H. (1959). Science, 129, 969

Mattingly, D. (1962). Journal of Clinical Pathology, 15, 374.

Plumpton, F. S., Besser, G. M., and Cole, P. V. (1969). Anaesthesia, 24, 3. Robinson, H. B., Mattingly, D., and Cope, C. L. (1962). British Medical Fournal, 1, 1579 .

Treadwell, B. L. J., Savage, O., Sever, E. D., and Copeman, W. S. C. (1963). Lancet, 1, 355.

\title{
Induction of Labour in Sheep and in Humans by Single Doses of Corticosteroids
}

\author{
J. K. G. MATI, D. F. HORROBIN, P. S. BRAMLEY
}

British Medical fournal, 1973, 2, 149-151

\section{Summary}

In sheep the administration of single intramuscular injections of dexamethasone into the fetus was shown to be an effective method of initiating parturition. In a controlled trial in women who had gone beyond the 41 st week of pregnancy 20 mg betamethasone in saline (six patients) or saline alone (five patients) was injected into the amniotic fluid. In the betamethasone-treated group delivery occurred 78.9 \pm 10.2 (S.D.) hours after injection while in the control group it occurred $323 \pm 62$ (S.D.) hours after injection $(P<0.01)$. In one woman with an anencephalic pregnancy intra-amniotic injection failed to initiate parturition but delivery occurred 88.5 hours after intramuscular injection of betamethasone into the fetus.

University of Nairobi, P.O. Box 30197, Nairobi, Kenya

J. K. G. MATI, M.B., M.R.C.o.G., Senior Lecturer in Obstetrics and

D. F. HORROBIN, B.M., D.PHIL., Professor of Medical Physiology (At present: Reader in Physiology, University of Newcastle upon Tyne, Newcastle upon Tyne NE1 7RU)

P. S. BRAMLEY, B.v.SC., PH.D., Lecturer in Animal Physiology (Present address: Grassland Research Institute, Hurley, Maidenhead)

\section{Introduction}

The obstetric induction of labour presents particular problems in a developing country. All existing methods require careful observation of the mother between the beginning of the induction and delivery. This can place an almost intolerable pressure on an already overloaded service. We have therefore attempted to test a new method which can be carried out as an outpatient procedure and which allows the woman to return home until an apparently normal labour begins a few days later.

Liggins and his co-workers have been largely responsible for developing the concept that the secretion of cortisol by the fetal adrenal is a key factor in the initiation of labour (Liggins, et al., 1967; Liggins and Kennedy, 1968; Liggins, 1968, 1969). Fetal cortisol also seems to play a major part in lung maturation and a naturally initiated normal delivery is usually a good indication that the lungs are mature and that respiratory distress is unlikely (Howatt. et al., 1965; Liggins, 1968, 1969). Liggins showed that premature labour could be induced in sheep by infusion of glucocorticoids into the fetus and that the lambs born as a result of this procedure could sustain respiration at a stage in development when this was not normally possible. Intrauterine fetal infusion is clearly not a simple method of inducing labour, and we therefore attempted to show that in sheep a single injection of glucocorticoid into the fetus could initiate labour without obvious ill effects on either fetus or mother. Having done this, we also attempted by means of a con- 